Document downloaded from:

http://hdl.handle.net/10251/63329

This paper must be cited as:

Andres, B.; Poler, R. (2015). Dealing with the Alignment Strategies Within the Collaborative Networked Partners. IFIP Advances in information and communication technology. 450:1321. doi:10.1007/978-3-319-16766-4_2.

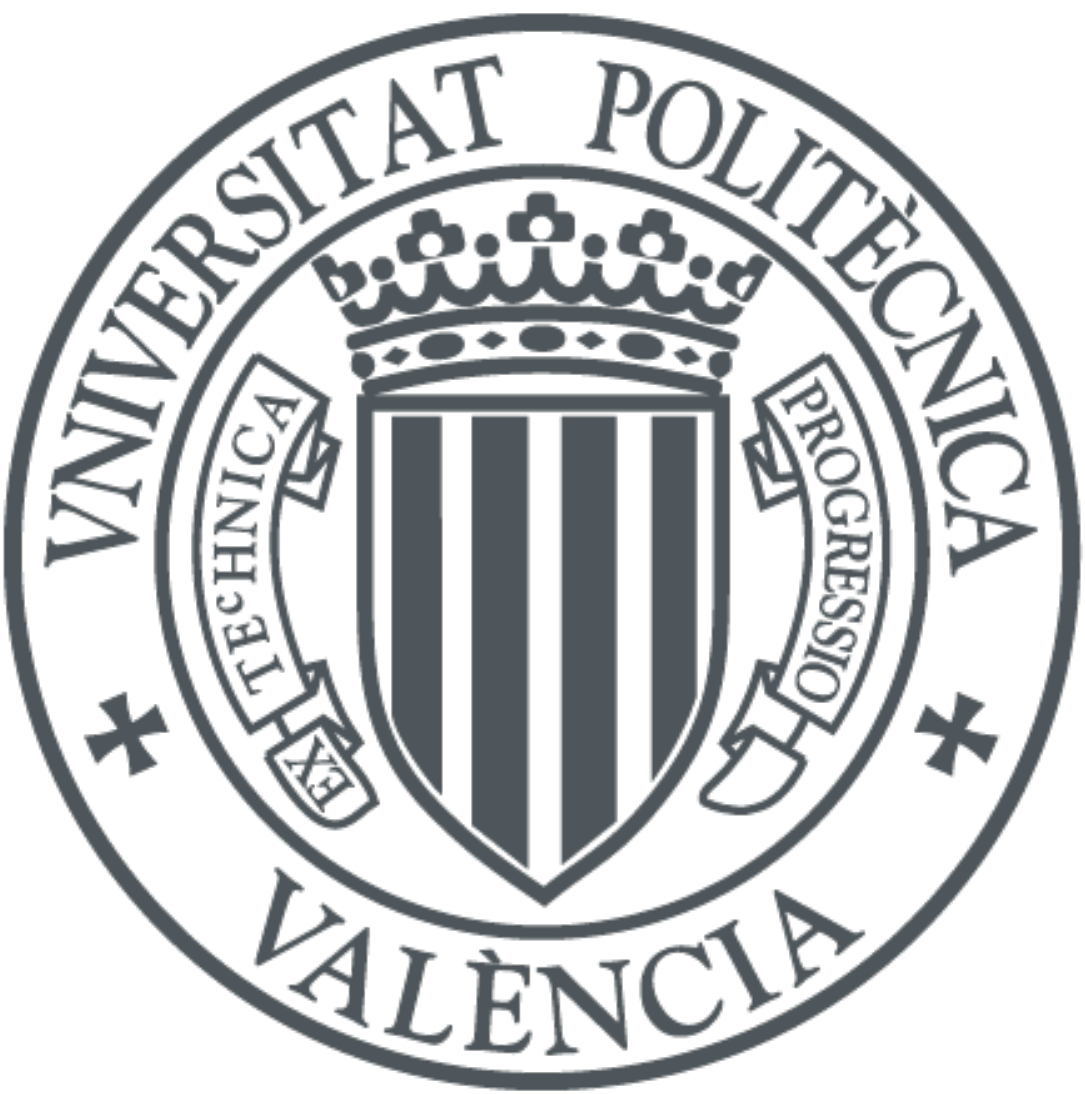

The final publication is available at

http://dx.doi.org/10.1007/978-3-319-24141-8_8

Copyright Springer

Additional Information 


\title{
Dealing with the alignment of strategies within the collaborative networked partners
}

\author{
Beatriz Andres ${ }^{1}$, Raul Poler ${ }^{1}$ \\ ${ }^{1}$ Centro de Investigación en Gestión e Ingeniería de la Producción. Escuela Politécnica \\ Superior de Alcoy, Universitat Politècnica de València. Centre d'Innovació i Investigació. \\ Calle Alarcón, 03801 Alcoy (Alicante) \\ \{beaanna, rpoler\}cigip.upv.es
}

\begin{abstract}
Over the last years, enterprises awareness towards establishing collaborative processes has significantly grown due to the benefits obtained when participating in a collaborative network $(\mathrm{CN})$. This paper is a continuation of the work developed by Andres and Poler [1] in which a set of collaborative processes are identified. This paper particularly focuses on the strategies alignment (SA) process, highlighting its influence on the success of a $\mathrm{CN}$. A preliminary framework is outlined to address the collaborative process of SA, consisting of a model, a method and a methodology. Highlighting the importance of the use of cloud-based systems to support small and medium enterprises (SMEs) to deal with the SA process. The implementation of the proposed framework allows identifying what are the strategies that are aligned and how its activation increases the network performance, resulting in more stable and sustainable collaborative relationships, and assuring the proper operation of the CNs.
\end{abstract}

Keywords: strategies alignment (SA), collaborative networks (CN), collaborative processes, sustainability, SMEs, cloud-based engineering systems.

\section{Introduction}

Along the last fifteen years, a wide research activity has been carried out in the $\mathrm{CN}$ context; this research especially focuses in small and medium enterprises (SMEs) due to their higher lack of resources and capabilities to conduct collaborative processes. A wide rage of models, guidelines and tools have been developed along the literature to assist enterprises to comply the requirements demanded by the CNs, and cope with the appearance of possible obstacles derived from the collaborative processes participation [2]. Despite the challenges enterprises have to face up when establishing collaborative processes, taking part in a $\mathrm{CN}$ leads them to obtain higher competitive advantages and greater degrees of agility, facilitating their survival in the current competitive and globalised environments.

${ }^{1}$ Please note that the LNCS Editorial assumes that all authors have used the western naming convention, with given names preceding surnames. This determines the structure of the names in the running heads and the author index. 
According to the definition provided by [3] a CN consist of a set of heterogeneous and autonomous entities, which collaborate to better achieve common or compatible goals. Each autonomous entity defines its own objectives and formulates its own strategies apart from defining a common goal. The raised strategies encompass a set of actions described to achieve the objectives defined, whose accomplishment is measured through key performance indicators (KPIs). Once the strategies are formulated the enterprises have to decide which ones activate in order to achieve the objectives defined and obtain the desired performance [4]. When deciding what strategies activate, an enterprise may opt for making this decision from an isolate perspective, that is, by only taking into account the extent to which the activation of its strategies will benefit the achievement of its own objectives. An enterprise that makes this decision, by only taking into account its own objectives, may trigger a contradictory situation in which the strategies activated by one enterprise positively influence the objectives defined in the same enterprise but could negatively influence the achievement of the objectives defined by the other network enterprises, leading to a partnership failure. On the other hand, an enterprise can opt for deciding what are the strategies to activate by considering not only its own objectives, but also taking into account the achievement of the objectives defined by the other network partners.

\subsection{Research question}

CNs are characterised by the heterogeneity of the enterprises and the objectives they define, consequently, a high diversity of strategies are formulated, to achieve these objectives, which at times might contradict one each other. In order to support the network partners on deciding about what strategies to activate, so that they positively influence all the objectives defined by network partners, a set of collaborative mechanisms are needed with the main aim of identifying the strategies that are aligned. In the light of this, a research question emerges:

What would be an adequate model, method and methodology to identify amongst all the strategies, formulated by the network partners, those that must be activated so that there are aligned and positively influence the objectives of all the partners?

The opportunities derived from the proper selection of strategies opens new ways to decide what strategies to activate, considering all the objectives defined by the enterprises. In this context, the research challenge emerges evolving from the null consideration of the objectives defined by all the network partners towards deciding what strategies to activate by considering how they affect to the objectives achievement of the rest of enterprises. The measurement of the increase of KPIs when certain strategies are activated will allow SMEs to identify what is the combination of strategies that results on higher increases on the KPIs. As will be justified then, the information gathering required to implement the framework proposed to deal with the SA process will be supported by cloud-based systems. Accordingly, the paper is organised as follows: Section 2 identifies how the SA process can benefit from the application of cloud-based systems; in Section 3 the SA concept is defined and a brief 
overview of how this concept has ben treated in the literature is given; Section 4 provides a summarised description of the proposed framework, consisting of a model, a method and a guideline to address the SA process; conclusions and future research lines are presented in Section 5.

\section{Benefits from Cloud-based Engineering Systems}

According to [5] the cloud-service term is understood as an Internet-based technology used as a repository of information and IT services provided to the enterprises (seen as a customers) that updates the data, computes the required issues (computation) and maintains the IT (software). The SA process, established in a $\mathrm{CN}$ context, involves a large diversity of SMEs having their own information. To address the proposed SA model interoperable information systems are required to exchange the data demanded. Cloud-based systems allow achieving data interoperability between different applications belonging to different SMEs; exchanging, connecting and integrating the data required to feed the model developed to deal with the SA process [6]. Considering the characteristics affecting the widely distributed SMEs, for which the proposed SA framework is designed, cloud-computing resources contribute to overcome some limitations of the SMEs in terms of (i) increasing their capability to process and storage the information, (ii) reducing the lack of interoperability in their applications, and (iii) shortening their limited computed power, with appropriate computational resources, technologies and software. One useful application of cloudbased systems in the context of SA is the integration of the simulation software used to solve the proposed SA model: AnyLogic $\mathbb{B}$ [7]. This system dynamics simulation software will be included in the cloud in order to support all the enterprises, belonging to the collaborative network, on the decision making of which strategies to activate in order to be aligned one with each other.

\section{Definition and State of Art}

In this section a definition of what in this paper is meant by the SA concept, is offered. Besides this, a brief overview on how the alignment concept has been treated in the literature is given.

Strategies alignment (SA) concept. Considering that the strategies are the set of actions to be performed in order to fulfil the objectives defined, there are characterised by being aligned when: each activated strategy not only promotes the achievement of the objectives defined by the enterprise that raises such strategy, but also positively influences the accomplishment of the objectives defined by the rest of the network partners. The SA concept is linked with the strategies complementarity, in which two or more strategies, apart from being able to exist together harmoniously if simultaneously activated (compatibility), enhance the benefits obtained in the associated objectives, receiving positive influences from the set of activated strategies 
The literature has used different terms to refer to the alignment concept in the CNs context, such CN participants' alignment [8], strategic alliance [9], collaborative strategy [10] or values alignment [11]. As regards the alignment in the specific context of strategies, different works have been developed, by considering in most of the cases the alignment of two particular strategies (table 1).

The analysis of the selected works has allowed identifying a common feature about how the alignment concept is treated. Concluding that, the approaches developed so far to deal with the alignment of strategies deals with the strategies compatibility. What is to say that, the alignment term is used to promote the simultaneous activation of pairs of specific strategies, which make a good combination, but does not involves, necessarily, that the enterprises performance increase when compatible strategies are activated. Accordingly, none of the works, provided so far, give a global view of the whole range of strategies defined by all the enterprises of the $\mathrm{CN}$. In the light of this, the SA framework proposed in this paper goes further and develops a holistic approach identifying complementary strategies, in which the collaborative network system is analysed as a whole, considering all the strategies formulated by the enterprises that comprise it. The holistic nature of the proposed approach allows determining how the objectives of each company behave (increasing or decreasing its performance levels) as a result of the synergies arising from the activated strategies.

Table 1. Alignment of specific strategies and authors.

\begin{tabular}{ll}
\hline Alignment of specific strategies & Authors \\
\hline Business Strategy \& IT Strategy & Cuenca et al. [12] \\
Business Strategy \& Information Assurance Efforts & Jean-Noël et al. [13] \\
Business Strategy \& e-Business & Raymond and Bergeron [14] \\
Supply Strategies & Cousins [15] \\
Global Sourcing Strategies & Selen and Ashayeri [16] \\
Marketing Strategy \& Sourcing Strategy & Green et al. [17] \\
Supply Chain Configuration \& Distribution Channels & Wu et al. [18] \\
Product Design Strategies & Dell'Era and Verganti [19] \\
Product \& SC characteristics & Lyons and Ma'aram [20] \\
Product \& SC Processes & Stavrulaki and Davis [21] \\
Green SCM \& Business Strategy & Whitelock [22] \\
\hline
\end{tabular}

\section{Research Contribution in Strategies Alignment}

The strategies alignment process is considered a key factor that, if carried out, leads the $\mathrm{CN}$ to have higher levels of performance, and therefore, success. The problem identified in this paper is the strategies misalignment, which may lead to partnership failure. In order to deal with this relevant problem, the paper bases its research on a theoretical body of knowledge regarding Collaborative Networks, Industrial Management, and System Dynamics. The research scientific methodology used has its ground on the Constructive Research method [23]. A framework consisting of (i) a model, to represent the links between the objectives and the strategies formulated by all the networked partners, (ii) a method, selected to solve the particular modelled process, the SA, and (iii) a methodology, to guide the $\mathrm{CN}$ enterprises on how to apply 
the model, to solve the specific problem of SA, is proposed. This framework identifies the set of strategies to activate in order to be aligned.

\subsection{Strategies Alignment Modelling}

The SA model addresses the decision making of what strategies to activate though an approach that allows to identify the set of strategies that if activated positively influence (or its negative influence is minimum) all the objectives defined by all the network partners. The model computes the increase (or decrease) of the KPIs, used to measure the objectives, depending on what strategies are activated. Accordingly, the model is based on deciding which strategies to activate so that the increase of the KPIs is maximised. The set of parameters characterising the SA model are depicted in (table 2). These parameters allow defining the function that models the influence the strategies exert over the KPIs (fig 1).

Table 2. Parameters and its classification in systems dynamic

\begin{tabular}{|c|c|c|}
\hline Index & & \\
\hline net set of netwo & $\boldsymbol{k} \quad$ set of KPIs $(k=1, \ldots, K)$ & \\
\hline set of enterp & $s \quad$ set of strategies $(s=1, \ldots, S)$ & \\
\hline set of object & es $(o=1, \ldots, O)$ & \\
\hline Parameters & & Type of variable \\
\hline$k p i_{i x k}$ & KPI $k$ defined by enterprise $i$ to measure the objective $x$ & \\
\hline$k p i_{i}$ & KPI at enterprise level (the sum of the $k p i_{i x k}$ ) & Auxinary varrabies \\
\hline$k p i_{\text {net }}$ & KPI at network level (the sum of the $k p i_{i}$ ) & \\
\hline$s t r_{i s}$ & Strategy $s$ defined by the enterprise $i$ & \\
\hline u_str ${ }_{i s}$ & Units of strategies to activate of $s t r_{i s}$ & \\
\hline c_str ${ }_{i s}$ & Cost of one unit of strategy $s t r_{i s}$ & \\
\hline$v a l \_s t r_{i s \_} k p i_{i x k}$ & $\begin{array}{l}\text { Value estimated by the enterprise defining the increase or } \\
\text { decrease of the } k p i_{i x k} \text { when one unit of } s t r_{i s} \text { is activated }\end{array}$ & \\
\hline$t i \_s t r_{i s}$ & Time of initialisation of $s t r_{i s}$ & \\
\hline$t i \_s t r_{i s}$ & Time of finalisation of $s t r_{i s}$ & Auxiliary Variables \\
\hline$d_{1 \_} s t r_{i s}$ & $\begin{array}{l}\text { Delay time, period of time in which, once the } s t r_{i s} \text { is initiated, } \\
\text { the } s t r_{i s} \text { does not exerts influence over the } k p i_{i x k}\end{array}$ & $\left(s t r_{i s}\right)$ \\
\hline$d_{2 \_} s t r_{i s}$ & $\begin{array}{l}\text { The influence that } s t r_{i s} \text { exerts on the } k p i_{i x k} \text { is not immediate, } \\
\text { unlike it takes a time to reach the maximum level of influence } \\
\left(v a l \_s t r_{i s \_} k p i_{i x k}\right)\end{array}$ & \\
\hline$s l o p e \_s t r_{i s \_} k p i_{i x k}$ & The progressive influence during $d_{2 \_} s t r_{i s}$ & \\
\hline$d_{4 \_} s t r_{i s}$ & Duration of strategy $s t r_{i s}$ & \\
\hline inf_str ${ }_{i s \_} k p i_{i x k}$ & Maximum level of influence of $s t r_{i s}$ in $k p i_{i x k}$ & \\
\hline$b i$ & Budget owned by enterprise $i$ to activate the strategies & Stock Variablec \\
\hline$\nabla k p i_{i x k}$ & Increase of the KPI when the strategies are activated & Stock Varıables \\
\hline$F \_i n f \_s t r_{i s \_} k p i_{i x k}$ & $\begin{array}{l}\text { Function of influence that the } k p i_{i x k} \text { experiences when the } \\
\text { strategy } s t r_{i s} \text { is activated (fig 1) }\end{array}$ & Flow Variable \\
\hline
\end{tabular}

The objective function is defined by maximising the parameter $k p i_{\text {net }}$ through modifying the decision variables defined by $t i_{-} s t r_{i s}$ and $u_{-} s t r_{i s}$. 


$$
\begin{gathered}
k p i_{n e t}=\sum_{i} i k p i_{i} \\
k p i_{i}=\sum_{i} \nabla k p i_{i x k} \\
\nabla k p i_{i x k}=\int F_{\inf _{s t r}}{ }^{i s_{k p i} i x k}(t) \cdot d t
\end{gathered}
$$

$F_{-}$inf _str ${ }_{i s-} k p i_{i x k}$$$
=\left\{\begin{array}{l}
0 ; t<t_{i-} s t r_{i s}+d_{1-} s t r_{i s} \wedge t<t_{f-} s t r_{i s} \\
\text { slope_str }_{i s_{-}} k p i_{i x k} ; t_{i-} s t r_{i s}+d_{1 \_} s t r_{i s} \leq t \leq t_{i \_} s r_{i s}+d_{1 \_} s t r_{i s}+d_{2 \_} s t r_{i s} \\
\text { inf_str }{ }_{i s-} k p i_{i x k} ; t_{i \_} s t r_{i s}+d_{1 \_} s t r_{i s}+d_{2 \_} s t r_{i s}<t \leq t_{f \_} s t r_{i s}
\end{array}\right.
$$

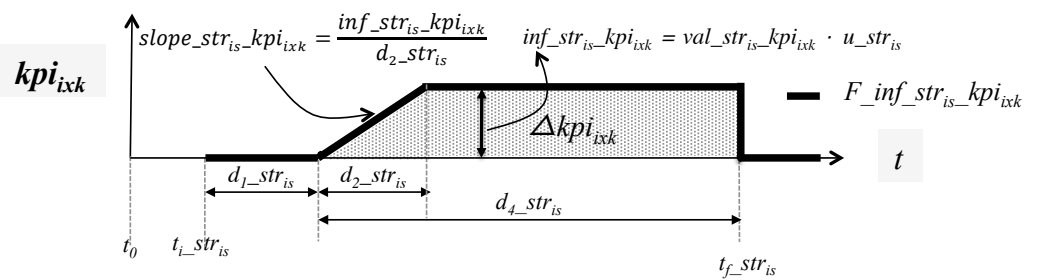

Fig. 1. Function modelling the KPIs behaviour when a strategy is activated $F_{-} s t r_{i s-} k p i_{i k}$.

\subsection{Method: Systems Dynamic (SD)}

The systems dynamic [24] is the method selected to solve the SA model, due to allows characterising the causal relationships between the strategies and the objectives, and models the influences that the objectives experience when certain set of strategies are activated. The parameters that characterise the model are arranged according to the classification given by SD method: stock variables, flow variables and auxiliary variables (table 2, Type of Variables column) [25]. The tool used to solve the SA model is AnyLogic ${ }^{\circledR}$ [7], allowing simulating in SD. This software includes an optimiser package that allows obtaining the best set of parameters $\left(t i_{-} s t r_{i s}\right.$, $u_{-} s t r_{i s}$, ) that maximise the network performance $\left(k p i_{n}\right)$.

\subsection{Methodology}

The collection of steps that allows enterprises to identify the set of aligned strategies that optimise the network performance is described. The methodology consist of: (i) selecting the enterprises that participate in the SA process; (ii) identifying for each enterprise the objectives defined: the $k p i_{i x k}$ used to measure these objectives and the strategies formulated $\left(s t r_{i s}\right)$ to be potentially activated; (iii) gathering the data: each enterprise estimates the value, val_str ${ }_{i s-} k p i_{i x k}$, that determines the strategies $\left(s t r_{i s}\right)$ influence on the $k p i_{i x k}$ when the first ones are activated, besides this, all the data regarding the strategies characterisation is also collected (costs and durations). The use of cloud-based systems support enterprises on gathering the data; (iv) feeding the model with the gathered data; (v) the SA model is simulated in AnyLogic ${ }^{\circledR}$ software. 
The number of units to activate of each strategy, $u_{-} s t r_{i s}$, and the time unit in which each strategy is initiated, $t_{-} s t r_{i s}$, are determined, maximising the $k p i_{n}$. The use of cloud-based systems is used to provide to all the collaborative SMEs with software. We refer readers to Andres and Poler [25] for a detailed numerical example applying the above-developed model.

\section{Conclusions and future work}

This paper focuses on the SA process, addressing it through modelling the influences that the strategies exert on the KPIs, defined to measure the objectives achievement.

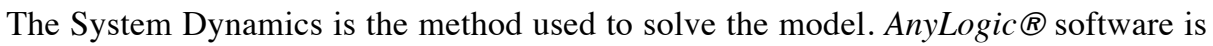
selected to implement the modelled process of SA. The provided approach supports the decision making process of which strategies activate at enterprise level from an holistic perspective considering all the strategies defined by the enterprises of a $\mathrm{CN}$, allowing obtaining optimal network performance levels. Cloud-based systems are useful tools to support enterprises on gathering the information required by the SMEs in order to feed and implement the model. Despite the advantages obtained from the application of the SA framework, there is a limitation related with the information gathering, as regards the estimation of the value $v a l_{-} s t r_{i s} k p i{ }_{i x k}$, specially if the strategy $s r_{i s}$ has never been activated or there is a lack of information flow between the $\mathrm{CN}$ enterprises. The drawbacks as regards the information exchange and uncertainty inherent to $\mathrm{CN}$ must be considered in the formulation of the model and definition of the methodology. In the light of this, future work is lead to (i) extend the work developed so far defining a complete model and methodology in order to deal with the identified limitations, (ii) validate the developed approach in a real supply network, and (iii) demonstrate the usefulness of the developed contribution through simulations comparing collaborative and non-collaborative scenarios, of the decision making regarding the strategies activation.

Acknowledgments. This work was funded by the Programa Val $i+d$ para investigadores en formación (ACIF).

\section{References}

1. Andres, B. and Poler, R. (2014). Research on Collaborative Processes in Non-Hierarchical Manufacturing Networks. In: L.M. Camarinha-Matos et al. (Eds.): DoCEIS 2014, IFIP AICT 423, pp. 21-28, 2014

2. Andres, B. and Poler, R. (2013). Relevant problems in collaborative processes of nonhierarchical manufacturing networks. Journal of Industrial Engineering and Management, 6 (3): 723-73.

3. Camarinha-Matos, L.M. and Afsarmanesh, H.: Collaborative Networks: A new scientific discipline. Journal of Intellient Manufacturing 16 (4), 439-452 (2005)

4. Andres, B. and Poler, R. (2014). Computing the strategies alignment in Collaborative Networks In: K. Mertins et al. (eds.), Enterprise Interoperability VI, Springer International Publishing Switzerland 
5. Bal, J., Issa, A., \& Ma, X. (2014). Orchestrating New Markets Using Cloud Services. In Collaborative Systems for Smart Networked Environments (pp. 161-168). Springer Berlin Heidelberg.

6. Mell, P., Grance, T. (2009) The NIST definition of cloud computing. National Institute of Standars and Techonology, 53 (6), 20.

7. Anylogic (2014) AnyLogic $®$ Software 7.0.3 University http://www.anylogic.com/

8. da Piedade Francisco, R., Azevedo, A., \& Bastos, J. (2010). Managing performance to align the participants of collaborative networks: case studies results. In Collaborative Networks for a Sustainable World (pp. 545-552). Springer Berlin Heidelberg.

9. Cante, C.J., Calluzzo, V.J., Schwartz, D.P. and Schwartz, T.M. (2004),"Strategic alliances in food and beverage and executive recruiting industries", Supply Chain Management: An Int Journal, Vol. 9 Iss 3 pp. 230 - 240

10. Campos, P., Brazdil, P., \& Mota, I. (2013). Comparing Strategies of Collaborative Networks for R\&D: an agent-based study. Computational Economics, 42(1), 1-22.

11. Macedo, P., \& Camarinha-Matos, L. M. (2013). A qualitative approach to assess the alignment of Value Systems in collaborative enterprises networks. Computers \& Industrial Engineering, 64(1), 412-424.

12. Cuenca, L., Boza, A., \& Ortiz, A. (2011). An enterprise engineering approach for the alignment of business and information technology strategy. International Journal of Computer Integrated Manufacturing, 24(11), 974-992.

13. Jean-Noël Ezingeard Elspeth McFadzean David Birchall, (2007),"Mastering the art of corroboration", Journal of Enterprise Information Management, Vol. 20 Iss 1 pp. $96-118$

14. Raymond, L., Bergeron, F. (2008),"Enabling the business strategy of SMEs through e\#business capabilities", Industrial Management \& Data Systems, Vol. 108 Iss 5 pp. 577 595

15. Cousins, P.D. (2005),"The alignment of appropriate firm and supply strategies for competitive advantage", International Journal of Operations \& Production Management, Vol. 25 Iss 5 pp. $403-428$

16. Selen, W., \& Ashayeri, J. (2008). Global sourcing strategy alignment using business intelligence: a conceptual framework. International Journal of Procurement Management, 1(3), 342-358.

17. Green Jr, K. W., Whitten, D., \& Inman, R. A. (2012). Aligning marketing strategies throughout the supply chain to enhance performance. Industrial Marketing Management, 41(6), 1008-1018.

18. Wu, T., Wang, W., Tang, C. S., Liu, D., Gao, F., \& Fang, C. (2008). How do foreign cosmetics companies align their supply chains and distribution channels in China?. International Journal of Logistics: Research and Applications, 11(3), 201-228.

19. Dell'Era, C., \& Verganti, R. (2010). Collaborative strategies in design-intensive industries: knowledge diversity and innovation. Long Range Planning, 43(1), 123-141.

20. Lyons, A. C., \& Ma'aram, A. (2014). An examination of multi-tier supply chain strategy alignment in the food industry. International Journal of Production Research, 52(7), 19111925 .

21. Stavrulaki, E., Davis, M. (2010),"Aligning products with supply chain processes and strategy", The International Journal of Logistics Management, Vol. 21 Iss 1 pp. 127 - 151

22. Whitelock, V. G. (2012). Alignment between green supply chain management strategy and business strategy. International Journal of Procurement Management, 5(4), 430-451.

23. Kasanen, E., K. Lukka, and A. Siitonen, The Constructive Approach in Management Accounting Research. Journal of Management Accounting Research, 1993. Vol 5. p. 21

24. Forrester, J.W. (1961) Industrial Dynamics (MIT Press and Wiley, New York)

25. Andres, B. and Poler, R. (2014). Identifying the Strategies to be activated for Optimising the Performance in Collaborative Networks. 8th International Conference on Industrial Engineering and Industrial Management. 